The goal of this paper presents the main characteristics of the computer esthetics, art and robotics and right away describes some artistic works developed in the Laboratory of research in art and virtual reality of the University of Brasilia, supported by the National Council for Scientific and Technological Development (CNPq).

Keywords: Computer art, art and robotics, post-human. 


\section{Arte computacional e robótica}

\section{Suzete \\ VENTURELLI}

Mario

MACIEL

O texto apresenta primeiramente as principais características da arte computacional e robótica e em seguida descreve alguns trabalhos artísticos desenvolvidos no Laboratório de pesquisa em arte e realidade virtual da Universidade de Brasília, que contou com apoio do Conselho Nacional de Tecnológico e Desenvolvimento Científico (CNPq).

Palavras-chave: Arte computacional, arte e robótica, pós-humano. 


\section{Introdução}

Na relação entre arte e robótica, nos nossos trabalhos, buscamos adotar conceitos considerados subjetivos no contexto tecnocientífico para classificar ou detectar certas situações tais como, siga em frente "alguns metros". O que queremos dizer é que aplicamos na criação de um algoritmo artístico conceitos que envolvem certa imprecisão. Na área da ciência, as primeiras noções da lógica dos conceitos "vagos" foi desenvolvida pelo lógico polonês Jan Lukasiewicz, em 1920, que introduziu conjuntos com graus de pertinência sendo $0,1 / 2$ e 1 e, mais tarde, expandiu para um número infinito de valores entre 0 e 1 .

Em resumo, na teoria da matemática clássica, os conjuntos são denominados "crisp" e um dado elemento do universo em discurso, o domínio, pertence ou não pertence ao referido conjunto. Na teoria dos conjuntos "fuzzy" existe um grau de pertinência de cada elemento a um determinado conjunto. Fuzzy é um adjetivo, cujo conceito passa sempre pelo vago, o acaso, o indistinto e o incerto (ALMEIDA e EVSUKOFF, 2003, 169).

Outro conceito importante no nosso trabalho é o de serendipity, ou serendipite em português, que significa a descoberta, de forma acidental, de algo que tenha ou desperte para algo diferente do que foi anteriormente planejado. Pode ainda significar a descoberta, também acidental, de alguma coisa que seja agradável, artística etc. Ao ser mos um pouco flexíveis na busca do significado do termo computacional, que deriva de computação, é necessário voltar no tempo, quando a habilidade de fazer objetos, de somar e de subtrair foi desenvolvida pelas pessoas. Esse termo ${ }^{1}$ quer dizer atualmente, o procedimento de calcular determinando algo por métodos matemáticos ou lógicos.

O interesse, por exemplo, pela relação entre arte e matemática, por sua vez, como atividade integrada é muito antigo e surge em diferentes sociedades simultaneamente ou em períodos diferentes. Por exemplo, essa integração torna-se evidente em objetos, ferramentas e estruturas cujas inovações técnicas na maioria das vezes coincidem com mudanças que ocorrem em paralelo no contexto estético.

Um bom exemplo são os sistemas astrológicos e de calen- 
dários, que foram elaborados através de muitas culturas, combinaram dados empíricos observados com narrativas mitológicas ricamente expressivas como uma maneira de interpretar e disseminar e ao mesmo tempo conservar os dados obtidos a partir de observações feitas diretas da natureza (GREENBERG, 2007: 3).

As tecelagens, tecidos, gravuras, mandalas, desenhos, objetos e ferramentas de culturas ao redor do mundo sempre empregaram um ou outro padrão algorítmico complexo baseado sobre princípios matemáticos, entretanto a maioria freqüentemente não foi desenvolvida por matemáticos. Antes, estes desenvolvimentos parecem refletir um impulso humano universal de combinar noções qualitativas estéticas com sistemas analíticos para estruturar dados visuais e formais.

Muito além da imaginação, com o desenvolvimento tecnológico, na era atual, imagens computacionais, de cyborgs, de andróides e de robôs passaram a interessar os artistas abrindo espaço para a origem da estética pós-humana, termo adotado por autores como a teórica Lúcia Santaella. O termo pós-humano aparece notadamente nos campos da ciência-ficção e da estética computacional e está estritamente relacionado com a utilização das tecnologias contemporâneas e com a biotecnologia.

Uma importante indagação que nossas pesquisas avaliam é saber qual é o papel da arte nessa nova fase, onde o futuro do ser humano, psicológico, biológico, cultural, mental, espiritual, social e artístico é também condicionado pelas pesquisas tecnocientíficas?

$\mathrm{Na}$ procura de algumas respostas, desde o século 20, verificamos que se propagaram exposições, festivais e prêmios incentivando ou buscando apresentar as propostas de apoio ou de crítica dos artistas sobre o assunto. Historicamente, nos anos 1960 surgem as primeiras máquinas robóticas propostas por artistas, a partir da arte cinética que contribuiu para trazer novamente a máquina para o centro do debate artístico.

De certa maneira, as pesquisas em robótica estão pretendendo fazer com que as máquinas se humanizem, isto é, que se perceba que máquinas e humanos podem coexistir. 


\section{Arte e robótica: bots ${ }^{2}$}

A arte computacional e sua estética não tratam somente dos aspectos imagéticos, mas também visam à criação transdisciplinar envolvendo campos do conhecimento que envolve a engenharia maquínica e biológica, como as propostas em arte e robótica.

Por exemplo, na construção da vida artificial, entendemos que repassamos características humanas, dentre elas a necessidade de aumentar nossas capacidades sensoriais e perceptivas da realidade. Entretanto, na vida artificial, algo diferente acontece. Não sabemos se o termo subjetividade artificial seria correto para designar uma característica dos seres virtuais, mas podemos dizer que assistimos ao surgimento de um novo tipo de percepção em relação às máquinas computacionais, que é a percepção do real ou do virtual por um ser artificial.

A partir do momento em que seres artificiais possuem sensores ou são constituídos de redes neurais e atuadores que permitem a sua expressão, eles preenchem as condições para acenderem ao estatuto de seres vivos. É nesse momento, que a relação do criador com sua obra muda completamente, ou seja, a relação é de igual para igual.

Alguns artistas viram nessas invenções possibilidades delas serem adequadas a propósitos artísticos e passaram a trabalhar com a idéia da criação de seres virtuais, que trazem certa autonomia em relação ao real. Entramos assim num segundo nível de interação com o objeto, que não depende somente da interação com o real para existir, ou seja, é um objeto de alto nível de complexidade que estabelece interatividade entre elementos da vida artificial e da Inteligência Artificial. Essa pesquisa se insere no que estamos denominando de roboarte, que compreende a robótica, enquanto cruzamentos entre telemática, biotecnologia e nanotecnologia informam o processo de trabalho de artistas, designers e arquitetos (ASCOTT, 2003, p.273).

Uma análise não muito profunda das conjunturas da sociedade brasileira, ou mesmo mundial, mostra uma instabilidade em vários fatores em relação às várias classes sociais que não 
pode ser ignorado. As desigualdades vão do âmbito econômico ao cultural e educacional, todas relacionadas umas às outras. No âmbito educacional verifica-se uma discrepância bem grande. Ao compararmos as regiões sudeste e nordeste, por exemplo, já se verifica que as taxas de evasão e os desempenhos dos alunos são bem diferentes. Pode-se observar ainda que a quantidade de pessoas seja tão menor quanto maior o nível educacional. Somente uma pequena parcela da população entra em uma faculdade ou universidade, e um grupo ainda menor se forma ou faz algum curso de pós-graduação.

Nesse projeto pretende-se por em um mesmo espaço dois pontos máximos dessa desigualdade, fazendo o contraponto entre tecnologia e nível educacional baixo. A tecnologia será representada por dois robôs, em que um será guiado por um espectador e o outro o seguirá. O nível educacional baixo terá como ponto principal placas e anúncios com erros encontradas em estradas e ruas pelo Brasil.

Para a construção do robô está sendo utilizada a plataforma LEGO ${ }^{\circledR}$ Mindstorms 9797 ${ }^{\circledR}$ NXT, que consiste de um bloco lógico programável, NXT, de sensores de luz, de som, de toque e ultra-sônico, três servos motores com encoder acoplados, uma bateria recarregável, além de peças técnicas diversas de LEGO ${ }^{\circledR}$, kit este distribuído pela EDAcom ${ }^{\circledR}$.

O bloco programável é composto por um processador 32-bit ARM7 microcontroller @ 48MHz com um co-processador 8-bit AVR microcontroller @ 4MHz. Ele possui 4 portas de entrada e 3 de saída, além de um display, LCD, de 100x64 pixel e um alto-falante. Há duas vias de comunicação com o bloco programável: USB 2.0 e bluetooth. O sensor ultra-sônico é composto por um emissor e um receptor de ondas sonoras, medindo o tempo necessário para que o som emitido vá até o obstáculo e volte, dando uma medida da distância até o objeto. Como a propagação do som no ar se dá a uma velocidade constante para os parâmetros utilizados, tem-se que a distância do objeto será metade da distância percorrida pelo som, ida e volta, donde se obtém a distância do robô ao objeto.

Segundo testes realizados na área da robótica o posicionamento ótimo do sensor ultra-sônico é aquele em que o sensor 
fica horizontalmente alinhado com o solo. Outro fator importante no uso desse sensor é que entre cada medição devesse ter um intervalo para que os ecos de uma medição não interfiram em outras; esse tempo pode variar para cada sensor, mas pode-se obter um valor de segurança, que, segundo usuários, um valor igual ou superior a 75 milissegundos já é suficiente. A programação do robô será feito com a linguagem NXC, linguagem desenvolvida por John Hansen, parecida com C, desenvolvida sobre o compilador da linguagem NBC. No LEGOß NXT a linguagem NXC funciona sobre o interpretador de bytecodes padrão do $L E G O \circledast$.

Para a detecção da localização dos robôs está sendo utilizada uma plataforma eletrônica de código aberto, a Arduino, desenvolvida para artistas, designers, aprendizado e interessados em criar objetos ou ambientes interativos. Essa plataforma tem várias portas de entradas e saída, controladas por um microcontrolador, para as placas USB ou serial, o microcontrolador ATMEGA8, e para placas bluetooth, o microcontrolador ATMEGA168. Com isso, a plataforma torna possível o sensoriamento do ambiente dando, posteriormente, uma resposta a cada evento do meio. No projeto está sendo testada uma placa Arduino BT, comunicação via bluetooth, enquanto a Arduino também será utilizada para o sensoriamento da posição dos robôs, e para cada posição a Arduino decidirá sobre uma determinada imagem que deverá ser exibida. A programação da placa Arduino se dá com uma linguagem baseada em $\mathrm{C} / \mathrm{C}++$, que suporta as construções comuns de $\mathrm{C}$ e algumas funções de $\mathrm{C}++$. Essa linguagem é compilada para a biblioteca AVRLibc que permite o uso de qualquer de suas funções.

Assim, esse projeto inicialmente, realizou o estudo e exploração do kit LEGO Mindstorms, bem como das ferramentas de programação para esse kit. Uma etapa posterior a esse estudo foi a construção dos primeiros modelos dos robôs. Uma primeira proposta foi a possibilidade de os robôs serem movimentados por patas. Essa tentativa inicial não teve sucesso, principalmente, devido a fragilidade dos robôs construídos com essa característica na plataforma LEGO, além da dificuldade de controle de movimentos. Com isso, decidiu-se por não mais usar 
robôs com patas, mas com rodas.

Outra alteração definida foi a de que o robô deveria, ao invés de ficar sempre andando aleatoriamente pelo espaço, ser controlado por um espectador humano, primando pela interação. Esse robô, assim, uma fonte de luz a laser apontado para uma trilha pelo espectador.

Quando não houver nenhum controle externo presente o robô deverá então continuar seguindo esse último modelo de trilha. Destacamos que nesse caso ocorre a implementação de algoritmo de inteligência artificial. Para o robô que segue luz, optou-se por um robô de tração diferencial, com dois sensores de luz posicionados à sua frente de modo a captar o foco de luz que deverá ser focado no chão a frente dos sensores. Iniciaram-se nesse ponto os estudos na plataforma Arduino, na plataforma de reconhecimento do posicionamento dos robôs.

Além da plataforma Arduino, estamos utilizando neste projeto o software Processing ${ }^{3}$, que é baseado na linguagem Java e permite a criação de imagens interativas, instalações artísticas e também alguns algoritmos completares com o sistema Arduíno de robótica. Processing é uma aplicação Java, que possibilita escrever programas como applets executados em browser de forma mais simplificada. Os programas desenvolvidos nele são denominados de sketches. Quando escrevemos line $(10,10,90,90)$ no Processing, queremos dizer que a linha será desenhada a partir do pixel 10 em x e 10 em y até o pixel 90 x e 90 y. Como toda linguagem de programação utiliza um sistema de coordenadas cartesianas $x$ e y para a criação de imagens. A linguagem também simula a coordenada do eixo $z$, que corresponde às imagens tridimensionais, ou 3D.

Existem basicamente dois modos de programação a denominada procedural e a orientada a objeto. São dois caminhos que se pode escolher, o primeiro usa funções, ou sub-rotinas, também denominadas de blocos de programação, que podem ser reutilizados, quando você precisar. O segundo usa o conceito de programação orientada a objetos (OOP), que tem a ambição de se aproximar, de modo abstrato, de modelos baseados no mundo real. Neste caso, o código é dividido em pequenos e independentes blocos de códigos chamados objetos. Pode-se 
também escrever programas usando os dois caminhos de modo híbrido. Um dos primeiros conceitos da programação é o de função. As funções ajudam a organizar o programa em blocos, que podem ser chamados quantas vezes for necessário dentro do programa. A estrutura, outro aspecto importante, pode ser entendida como a sintaxe que usamos para escrever uma linha de um código. Na programação procedural, são utilizados blocos de códigos, denominados de funções que podem ser chamados quando necessário.

Na programação orientada a objetos (OOP), a sintaxe é mais abstrata e metaforicamente se compara à criação de um jardim virtual, onde se criam classes, que são códigos de estruturas armazenadas separadamente. As classes poderiam ser vistas como as plantas, a grama, a água, as flores de um jardim virtual.

Os quatro conceitos básicos e fundamentais de toda linguagem de programação são: os métodos; as variáveis; as voltas (loops) e as bifurcações. Esses conceitos quando encaixados uns nos outros possibilitam a criação de programas mais complexos.

O método é uma palavra escolhida pelos desenvolvedores de uma linguagem de programação, que chama instruções específicas para realizar certa tarefa. São como palavras mágicas, pois toda vez que o processador do computador encontra o método no programa ele sabe o que fazer. Por exemplo, quando digitamos line $(10,10,250,190)$; estamos chamando o método line, que pré-existe como elemento da sintaxe da programação. Além de usar os existentes, podemos criar os seus próprios em qualquer linguagem que escolha trabalhar.

Em resumo, no Processing, assim como, em linguagens mais completas e complexas como Java, Python ou $\mathrm{C}$, existem termos pré-determinados, como os métodos aqui descritos, que foram criados pelos desenvolvedores de linguagens de programação.

Uma variável é um dado que contém uma informação, ou seja, uma variável contém um valor qualquer, exemplo: 5, 13, "OLá Mundo", 3.145 etc. A variável é identificada por um nome sem espaço exemplo: $x, y$, primeiroPrograma. Toda vez 
que estivermos usando uma variável estaremos aplicando o seu valor interno pré-determinado por nós ou pelo desenvolvedor de linguagem de programação. É importante destacar que todo momento usamos variáveis através dos programas que as utilizamos, sem saber. A posição da janela de um browser qualquer, por exemplo, é definida por uma variável, que contém todas as possíveis posições para serem mostradas na tela do monitor, além disso, contém outros dados como os caracteres de texto etc. O terceiro conceito que citaremos é o de loop. Volta é uma lista de instruções que pode ficar se repetindo até que uma condição a mande parar. Este conceito facilita a construção de programas. O conceito de bifurcação está relacionado com a idéia da lógica binária, onde um programa pode mudar de comportamento dependendo de eventos externos. Um bom exemplo são as imagens interativas. Exemplo: se estivermos numa estrada dirigindo e ela não estiver congestionada, continue. Se perceber uma faixa de pedestre então pare. Ou seja, ficaremos dirigindo enquanto a condição for verdadeira.

\section{Sistema interativo tangível (SiTang)}

Esta pesquisa se integra às pesquisas desenvolvidas no Laboratório de pesquisa em arte e realidade virtual e envolve vida artificial e está relacionada com a evolução da tecnologia computacional e com a área da mecatrônica, na medida em que máquinas foram desenvolvidas para programas inteligentes com capacidades antes caracterizadas como sendo exclusivamente do ser humano.

Nesse sentido, o objetivo desse trabalho é estudar a relação da arte e da robótica, destacando principalmente as possibilidades de criação de vida artificial e interatividade em sistemas tangíveis. Ou seja, pretende-se criar uma instalação com um Sistema Interativo Tangível portável utilizando dispositivos não convencionais de interação, que proporcionará a partir de um toque externo, o surgimento de vidas artificiais. A instalação será elaborada para ser colocada nas ruas e será composta por camadas de borrachas sensíveis ao toque. Como num jogo, o dispositivo quando pressionado iniciará um software de autô- 
matos celulares com leds, colados ao tapete de borracha sobre um muro ou parede de um edifício, como um tipo de grafite em constante modificação. A instalação é um convite para interações sociais urbanas, onde até a arquitetura participa do processo gerativo das imagens.

A introdução da vida artificial na criação artística repousa sobre a questão da interatividade, que é tradicionalmente concebida como a relação de um humano com uma máquina reativa, um diálogo com um sistema que é privado de consciência, mesmo se ele for inteligente.

\section{Notas}

1. Segundo o www.dictionary.com, computacional significa "The procedure of calculating: determining something by mathematical or logical methods".

2. Trabalho realizado com a participação dos bolsistas de Iniciação Científica do CNPq Breno Rocha, Gabriel Codo e Samuel Castro.

3. http://www.processing.org.

\section{Referências}

ALMEIDA, Paulo Eduardo Maciel e EVSUKOFF, Alexandre Gonçalves. Sistemas Fuzzy. IN: REZENDE, Solange Oliveira (Org.). Sistemas inteligentes: fundamentos e aplicações, São Paulo: Editora Manole, 2003.

COSTA, Mario. O Sublime Tecnológico. São Paulo: Experimento, 1995.

COUCHOT, Edmond. A tecnologia na arte: da fotografia à realidade virtual. Trad. Sandra Rey. Porto Alegre: Ed. UFRGS, 2003.

e HILLARIE, Norbert. L'Art Numérique: comment la

technologie vient au monde de l'art. Paris: Flammarion, 2003.

BENTES, Ivana (org.). Corpos virtuais. Rio de Janeiro: Centro Cultural Telemar, 2005.

DENNETT, Daniel. Consciousness Explained. Penguin, 1991.

GREENBERG, Ira. PROCESSING : CREATIVE CODING AND COMPUTACIONAL ART. NEW YORK, SPRINGER-VERLAG, 2007.

MARUSEK, David. We were out of our minds with joy. Revista Science Fiction Isaac Asimov, 1995. Site official da revista http://www.asimovs. $\mathrm{com} /$.

PINKER, Steven. Tábula rasa: negação contemporânea da natureza humana. São Paulo: Companhia das Letras, 2004.

RÖSSLER, Otto. E. Endophysics. In Real Brains, Artificial Minds. Ed. by J. L. 
Casti and A. Karlqvist. Nova lorque. North-Holland. 1987.

SALZANO, Francisco M. Biologia, cultura e evolução. Rio Grande do Sul: Editora da Universidade, 1993.

SVOZIL, Karl. http://www.lampsacus.com/documents/ SVOZILCOMPUTATIONALUNIVERSES.pdf . 2005. acessado em dezembro de 2007.

VENTURELLI, Suzete. Arte: espaço_tempo_imagem. Brasília: Edunb, 2004. WEIBEL, Peter. El Mundo como Interfaz. El paseante: la revolucion digital y sus dilemas. Ediciones Siruela, n.27-28, p.110-121, Madrid. 1998.

WEIBEL, Peter. El mundo como interfaz: 2000. Disponível em <http:// www.elementos.buap.mx/num40/pdf/23.pdf>. Acesso em janeiro de 2008

\section{MARIO MACIEL}

Arquiteto pela Universidade Federal do Rio Grande do Sul. Professor e pesquisador da Secretaria de Educação do Distrito Federal e doutorando em Arte pela Universidade de Brasília. Mestre em Arte, Departamento de Artes Visuais, IdA, UnB. Participu dos seguintes eventos: Congresso da Associação Nacional de Pesquisa em Artes Plásticas em Brasília, Encontro Internacional de Arte e Tecnologia da UnB em Brasília; Encontro internacional do CAllA Star em Fortaleza; Exposição de Mídia Arte em Cuba; Emoção Art.Ficial 2.0: convergências tecnológicas Itaú Cultural. Criação da programação visual do cátalgo da exposição Humano-pós-Humano, Centro Cultural Banco do Brasil, entre outros. Email: marel@marel.pro. br - www.marel.pro.br

\section{SUZETE VENTURELLI}

Doutorado em Artes e Ciências da Arte, Universidade Sorbonne Paris I, SORBONNE, França. Professora, artista, pesquisadora da Universidade de Brasília - UNB, Departamento de Artes Visuais e CNPq. Recebeu os seguintes prêmios: MAD03NET - categoria digital - Publicou o livro Arte: espaço_tempo_imagem pela EdunB em 2004. Prêmio Destaque para o trabalho Hubbub, concedido pelos Artistas Visuales Associados de Madrid, (AVAM) e Telefônica; Indicação do trabalho Kennetic World para o IX Prêmio Internacional de multimídia, China-Beijing; Indicação do trabalho artístico Silépticos Corpos para o Prêmio Cultural Sérgio Motta, Secretaria de Cultura do Estado de São Paulo; Menção Honrosa para o trabalho Laboratório de Imagem e Som concedido pelo Prêmio Moebius de Multimídia. Edital Universal CNPq.Email: suzetev@unb.br - www.suzeteventurelli. ida.unb.br 